\title{
EDITORIAL
}

\section{Evidence-based medicines for children: important implications for new therapies at all ages}

\section{A. Bush}

I $t$ has long been known that $50-90 \%$ of medications used in children are "off-label" or unlicensed, and this is associated with an increased risk of adverse events [1-14]. This means that some of the most vulnerable people in the European Union (EU), sick children, are being treated in a non-evidence-based, unregulated fashion. Even commonly prescribed respiratory medicines, such as short-acting $\beta_{2^{-}}$ agonists and antipyretics, have not been adequately studied in young children [15]. The risks of the present situation include: death or serious adverse events from overdosing; nonavailability to children of important medications; under-dosing leading to loss of efficacy; and the use of poor-quality formulae. Side-effects that may not affect adults might be very important in children; the effects of inappropriately prescribed inhaled steroids on growth is well known [16, 17], but could the use of parenteral steroids affect alveolar development in the first 2 years of life [18, 19]? Furthermore, there may be fundamental differences between adult and paediatric diseases; several studies have established that adult asthma is a chronic inflammatory disease, but many wheezing phenotypes in early childhood are not inflammatory and are thus poorly responsive to corticosteroids [20-29]. Some welcome steps have been taken to address this, with the publication of the evidence-based Medicines for Children by the Royal College of Paediatrics and Child Health [30], and the first edition of a Paediatric British National Formulary [31] replacing the generic one. However, evidence-based therapeutics requires evidence and this has been lacking.

There are several likely reasons for this scandalous lack of evidence-based paediatric pharmacotherapy. Much paediatric disease improves over time (many wheezing phenotypes [32], for example), whereas adult disease is more often chronic, progressive and requires prescription medicines long term. Thus, there is far less money to be made out of medication for children (although much to be wasted: nearly $€ 600$ million on antipyretics in Europe in 2004 [15]) and market forces have failed to generate sufficient enthusiasm in testing medications in children. Furthermore, there are special ethical and practical issues in carrying out research on children [33]. These include: the different pharmacokinetics at different ages, from the neonatal period to adolescence, so a single "paediatric" trial is never likely to be enough; and the challenging ethics of clinical trials in those too young to give consent for themselves.

CORRESPONDENCE: A. Bush, Dept of Paediatric Respiratory Medicine, Royal Brompton Hospital Sydney Street, London, SW3 6NP, UK. Fax: 44 2073518763. E-mail: a.bush@rbh.nthames.nhs.uk
However, the risks of giving untested medication to children must be set against this.

Following the lead of the American Food and Drug Administration [34], the European Commission has recently recognised this [35] and has proposed legislation to take the welcome steps needed to address this situation. Individual member states have also moved on this: for example, in the UK, $€ 30$ million has been set aside to establish the infrastructure to address this. The proposed new legislation will compel pharmaceutical companies to test all new medications in children or show good reason why this is not appropriate (for example, the disease for which the therapy is proposed does not occur in children). There will be penalties and incentives to ensure compliance. This may be thought to be dictatorial but the views of the Commission, which chime with those of many paediatricians, are that the "softly, softly" approach has comprehensively failed and compulsion is required to remove the "reverse ageism", which penalises children. From now on, testing medications in children will become an integral part of the licensing procedure and cannot be an "optional extra". For this reason, the proposed new legislation concerns us all and not just the paediatric community.

Central to the new legislation is the establishment of a new Paediatric Committee. Article 4 of the Council Common Position concerns the composition of this Committee. All 25 members of the EU will be invited to nominate two representatives, one of whom will be chosen. In addition, there will be three places for health professionals and three places for patients' representatives. Both the health professionals and patients will be chosen by the Commission after a call for expressions of interest. This call is likely to be published very soon after the directive enters into force (which is likely to be any time from autumn 2007). This Committee will have a large number of very important functions (table 1) and the respiratory community should prepare now to interact with the Committee as soon as it is constituted.

The paediatric investigation plan is to become an integral part of the introduction of all medicines in the EU. It should be submitted early. It must include details of which subpopulations of children will be studied. It may be appropriate to delay research in children until there is experience in adults, but early dialogue with the Paediatric Committee will be essential. The plan may be deferred or waived if appropriate, but only with the agreement of the Committee. Waivers would be on the grounds that the medication is likely to be ineffective, 


\section{TABLE 1 Functions of the new Paediatric Committee}

1. The scientific assessment and agreement of a detailed paediatric investigation plan for each newly proposed medication, and monitoring its implementation

2. The agreement of waivers and deferrals, the monitoring of compliance with the plan and ensuring that all data relating to the medication is in the public domain

3. The provision of free scientific advice to those interested in developing medicines for children. The committee will be concerned to foster good studies and avoid unnecessary ones. Ethics will be dealt with under existing provisions

4. The administration of a PUMA, a separate category for products exclusively designed for use in children

5. The monitoring of adverse events; part of any application will have to be a plan for gathering data on these. In particular high-risk situations, the committee may require specific studies to be put in place

6. The maintenance of a Europe-wide clinical trials register

7. The development of an inventory of paediatric needs, which will set the research agenda in the EU

8. The establishment of a network of centres performing clinical studies set up within Europe; the precise criteria for joining such a network are as yet unclear

9. To increase the high-quality information available concerning medicines for use in children, both for professionals and families. Properly tested medications will be marked with a logo (the letter "P" in blue lettering, surrounded by an outline of a star, also in blue) to ensure complete transparency

PUMA: Paediatric Use Marketing Authorisation; EU: European Union.

unsafe, irrelevant (the disease does not occur in children), or offers no new benefit to children. The Committee will have the power to revoke the waiver and will be consulted about compliance with the investigation plan prior to the granting of market authorisation. The Committee will mark with a symbol medication that has been tested in children. Furthermore, companies will be obliged to place the product on the market within 2 years of approval and must notify the Committee if they propose to withdraw them. Deferral would usually be because it is appropriate to perform the studies in adults first or because paediatric studies would take so long that there would be an unacceptable delay in marketing for adults. Another important component of the plan will be rigorous post-marketing surveillance, aiming not merely for early detection but also for early public reporting of any adverse events.

The rewards for compliance will include a 6-month extension of patent if companies have submitted a paediatric plan and adhered to it appropriately, even if it transpires that the medication is in fact not suitable for children and a licence is not authorised. The patent for orphan drugs will be extended from 10 to 12 years. Rewards will be withheld if investigation plans are flouted. Furthermore, there will be penalties; these are as yet unspecified but they will be "effective, proportionate, and dissuasive". Those infringing will be named publicly.

The intentions of the EU are obviously good and the plans appropriate; how can we ensure that they work? The first essential is absolute openness and integrity of process [36]. There is clearly an overlap between the interests of children and the interests of big pharma but they are not identical. The poor track record of parts of the industry has been catalogued in the past [37] and includes the suppression and massaging of data, and the performance of meta-analyses that somehow always come up in favour of the commissioning company [38]. Some of these issues have been addressed but there are, rightly, deep suspicions remaining. One function of the Paediatric Committee will be to set the research agenda by prioritising the really great questions that need to be answered immediately. Furthermore, it seems likely that the EU will not merely encourage new research but will ensure that resources are made available or, at the very least, that a favourable view will be taken of applications for funding of paediatric pharmacotherapy projects. However, there is an obvious opportunity for industry to hijack the process. For example, a trial of new medication against placebo is more likely to be favourable than new medication against current best therapy; pharma may favour the first but clinicians should mostly be interested in the second. Regulatory authorities also need to understand the almost total lack of value of the former in view of advancing management of disease. Professional societies such as the European Respiratory Society (ERS) must be proactive in assessing the current evidence using established Cochrane methodology, and determining a research priority, ready to present to the newly constituted Committee. Part of this process should be defining clinically as opposed to statistically significant end-points: is a temperature reduction of $<0.5^{\circ} \mathrm{C}$ by an antipyretic really important [15]? The declaration of conflicts of interest must be rigorous [37], and, above all, the ERS must be seen to stand independent of industry. We will be in competition for resources from all branches of paediatrics, and the European Lung White Book [39], now about to be revised, will allow the marshalling of the epidemiological evidence which should underpin the setting of priorities, another strong point for the ERS.

The second area to address is: who will actually do the work? The new legislation proposes the establishment of approved networks but, appropriately and unsurprisingly, has not gone into detail about how these will be identified and how they will interact with existing national networks. The ERS needs to ensure that criteria and common standard operating procedures are agreed and in place, in accordance with good clinical practice, before a centre can be recognised as being able to perform such studies. Potential centres need to be active now; they should identify what groups of diseases they can study, including a realistic idea of patient numbers, and what techniques they have available. We should be inclusive and also sensitive to ethical issues. Is it appropriate to use children in less wealthy parts of Europe to test expensive medications that are beyond the budget of their national health services? It is difficult to argue that this is compatible with the declaration of Helsinki. Furthermore, as the recent and disastrous trial of 
TGN1412 in the UK has shown, research is not without risks [36]. Studies in children must be performed to the highest ethical standards, and any study must be worthwhile and have the confidence of professionals, children and their families it is to be performed.

Finally, this proposed legislation plays to one of the major strengths of the European Respiratory Society, namely the interaction and close collaboration between respiratory specialists working in paediatrics and adult medicine. The introduction of future medication will have to cross age barriers, and the clinical trial requirements are different at different ages. Close collaboration will ensure that really appropriate investigation plans can be produced, avoiding the egregious blunders that ensue when a protocol suited for adults is uncritically applied to children [40]. Everyone will be hoping that these new proposals can make a real difference to evidence-based treatment of children and that the research agenda for safe treatment of children really can be at the forefront [41].

\section{REFERENCES}

1 Turner S, Nunn AJ, Fielding K, Choonara I. Adverse drug reactions to unlicensed and off-label drugs on paediatric wards: a prospective study. Acta Pediatr 1999; 88: 965-968.

2 Conroy S, Choonara I, Impicciatore P, et al. Survey of unlicensed and off label drug use in paediatric wards in European countries. European Network for Drug Investigation in Children. BMJ 2000; 320: 79-82.

3 McIntyre J, Conroy S, Avery A, Corns H, Choonara I. Unlicensed and off label prescribing of drugs in general practice. Arch Dis Child 2000; 83: 498-501.

4 Lifshitz M, Gavrilov Y, Gorodischer R. Off-label and unlicensed use of antidotes in paediatric patients. Eur J Cin Pharmacol 2001; 56: 839-841.

5 't Jong GW, Yulto AG, de Hoog M, et al. A survey of the use of off-label and unlicensed drugs in a Dutch children's hospital. Pediatrics 2001; 108: 1089-1093.

6 Craig JS, Henderson CR, Magee FA. The extent of unlicensed and off-label drug use in the paediatric ward of a district general hospital in Northern Ireland. Ir Med J 2001; 94: 237-240.

7 Pandolfini C, Impicciatore P, Provasi D, et al. Off-label use of drugs in Italy: a prospective, observational and multicentre study. Acta Paediatr 2002; 91: 339-347.

8 't Jong GW, van der Linden PD, Bakker EM, et al. Unlicensed and off-label drug use in a paediatric ward of a general hospital in the Netherlands. Eur J Clin Pharmacol 2002; 58: 293-297.

9 O'Donnell CP, Stone RJ, Morley CJ. Unlicensed and offlabel drug use in an Australian neonatal intensive care unit. Pediatrics 2002; 110: e52.

10 Horen B, Montastruc JL, Lapeyre-Mestre M. Adverse drug reactions and off-label drug use in paediatric outpatients. Br J Clin Pharmacol 2002; 54: 665-670.

11 Schirm E, Tobi H, de Jong-van den Berg LT. Risk factors for unlicensed and off-label drug use in children outside the hospital. Pediatrics 2003; 111: 291-295.

12 't Jong GW, Eland IA, Sturkenboom MC, van den Anker JN, Stricker BH. Determinants for drug prescribing to children below the minimum licensed age. Eur J Clin Pharmacol 2003; 58: 701-705.

13 Dick A, Keady S, Mohamed F, et al. Use of unlicensed and off-label medications in paediatric gastroenterology with a review of the commonly used formularies in the UK. Aliment Pharmacol Ther 2003; 15: 571-575.

14 Neubert A, Dormann H, Weiss J, et al. The impact of unlicensed and off-label drug use on adverse drug reactions in paediatric patients. Drug Saf 2004; 27: 10591067.

15 Hay AD, Redmond M, Fletcher M. Antipyretic drugs for children. BMJ 2006; 333: 4-5.

16 Doull IJ, Freezer NJ, Holgate ST. Growth of prepubertal children with mild asthma treated with inhaled beclomethasone dipropionate. Am J Respir Crit Care Med. 1995; 151: 1715-1719.

17 Doull IJ, Campbell MJ, Holgate ST. Duration of growth suppressive effects of regular inhaled corticosteroids. Arch Dis Child 1998; 78: 172-173.

18 Thibeault DW, Heimes B, Rezaiekhaligh M, Mabry S. Chronic modification of lung and heart development in glucocorticoid treated newborn rats exposed to hyperoxia or room air. Pediatr Pulmonol 1993; 16: 81-88.

19 Tschanz SA, Damke BM, Burri PH. Influence of postnatally administered glucocorticoids on rat lung growth. Biol Neonate 1995; 68: 229-245.

20 Saglani S, Malmström K, Pelkonen AS, et al. Airway remodeling and inflammation in symptomatic infants with reversible airflow obstruction. Am J Respir Crit Care Med 2005; 171: 722-727.

21 Lodrup-Carlsen KC, Jaakkola JJ, Nafstad P, Carlsen KH. In utero exposure to cigarette smoking influences lung function at birth. Eur Respir J 1997; 10: 1774-1779.

22 Stick SM, Burton PR, Gurrin L, Sly PD, Le Souëf PN. Effects of maternal smoking during pregnancy and a family history of asthma on respiratory function in newborn infants. Lancet 1996; 348: 1060-1064.

23 Young S, Le Souëf PN, Geelhoed GC, Stick SM, Turner KJ, Landau LI. The influence of a family history of asthma and parental smoking on airway responsiveness in early infancy. N Engl J Med 1991; 324: 1166-1173.

24 Stevenson EC, Turner G, Heaney LG, et al. Bronchoalveolar lavage findings suggest two different forms of childhood asthma. Clin Exp Allergy 1997; 27: 1027-1035.

25 Stick S, Arnott J, Landau LI, Turner D, Sly S, Le Souëf P. Bronchial responsiveness and lung function in recurrently wheezy infants. Am Rev Respir Dis 1991; 144: 1012-1015.

26 Turner SW, Young S, Landau LI, Le Souëf PN. Reduced lung function both before bronchiolitis and at 11 years. Arch Dis Child 2002; 87: 417-420.

27 Stein RT, Sherrill D, Morgan WJ, et al. Respiratory syncytial virus in early life and risk of wheeze and allergy by age 13 years. Lancet 1999; 354: 541-545.

28 Pelkonen AS, Hakulinen AL, Turpeinen M. Bronchial lability and responsiveness in school children born very preterm. Am J Respir Crit Care Med 1997; 156: 1178-1184.

29 Gappa M, Berner MM, Hohenschild S, Dammann CE, Bartmann P. Pulmonary function at school-age in surfactant-treated preterm infants. Pediatr Pulmonol 1999; 27: 191-198.

30 Medicines for Children. London, RCPCH, 2003. 
31 BNF for Children. London, BMJ Publishing Group, 2005.

32 Morgan WJ, Stern DA, Sherrill DL, et al. Outcome of asthma and wheezing in the first 6 years of life: follow-up through adolescence. Am J Respir Crit Care Med 2005; 172: 1253-1258.

33 McIntosh N, Bates P, Brykczynska G, et al. Guidelines for the ethical conduct of medical research involving children. Arch Dis Child 2000; 82: 177-182.

34 US Food and Drug Aministration. The Pediatric Research Equity Act. Public Law 108-155 December 32003. www.fda.gov/cder/pediatric/S-650-PREA.pdf.

35 Watson R. EU offers incentives to firms to produce medicines for children. BMJ 2006; 332: 1352.
36 Clinical trials in children for children, Lancet 2006; 367: 1953.

37 Smith R. Conflicts of interest: how money clouds objectivity. J Roy Soc Med 2006; 99: 292-297.

38 Bekelman JE, Li Y, Gross CP. Scope and impact of financial conflicts of interest in biomedical research: a systematic review. JAMA 2003; 289: 454-465.

39 European Respiratory Society. European Lung White Book. Sheffield, ERSJ Ltd, 2003.

40 Bush A. Strategies for effective collaboration between investigator sites and the pharmaceutical industry in pediatrics. Pediatric Drugs 2006; (in press).

41 Paediatric research should take centre stage, Lancet 2004; 364: 732 . 